\title{
Does the trade balance really matter for regions?
}

\author{
Pedro Nogueira Ramos
}

Received: 30 August 2005 / Accepted: 25 June 2006 /

Published online: 22 August 2006

(C) Springer-Verlag 2006

\begin{abstract}
This paper explores the reasons why regional economics and policymaking do not focus on the regional balance of payments, although relevant imbalances - comparing with countries - may arise. The main purpose of the paper is, on one hand, to gauge the importance of these external imbalances in regional economies, with that concept being confined to the trade (goods and services) account. Notwithstanding the limited data available, empirical evidence for EU regions is put forward to supporting the idea that regions meet more frequently trade imbalances of relevant size than those faced by countries. Discussion centers as well on why regions can run wider trade deficits than nations and it is argued that as regions avoid sustainability constraints they may even benefit from those imbalances.
\end{abstract}

JEL Classification $\mathrm{R}-10 \cdot \mathrm{R}-12 \cdot \mathrm{F}-41$

\footnotetext{
A first version of this paper was developed during a short term stay in REAL - Regional Economics Applications Laboratory, at the University of Illinois at Urbana-Champaign, in May 2005. Financial support from Fundação Calouste Gulbenkian, Lisbon, Portugal, and the hospitality of REAL are gratefully acknowledged. The author would like to thank Geoffrey Hewings as well for his stimulus and helpful comments. The contribution of two anonymous referees is also acknowledged. The usual disclaimer applies.
}

P. N. Ramos $(\varangle)$

Faculty of Economics, University of Coimbra,

Av. Dias da Silva, 165,

3004-512 Coimbra, Portugal

e-mail: pnramos@fe.uc.pt 


\section{Introduction}

The purpose of this paper is to gauge the importance of external imbalances in regional economies comparing with countries. The concept of external imbalance however confines here to the trade (goods and services) account, partly due to the lack of suitable data for regions, for extending the analysis to other levels of external payments. Even for trade - namely for interregional trade - official data are rarely available, preventing a direct assessment of trade disequilibrium. As a result, the great majority of literature is compelled to focus on indirect measures of the external imbalances such as the gaps between regional savings and the regional investment.

Bayoumi and Rose (1993), Dekle (1996), Helliwell and McKitrick (1999) and Decressin and Disyatat (2000), that fit into a well known issue of economic theory, the Feldstein-Horioka (FH) puzzle, ${ }^{1}$ are representative of that approach. ${ }^{2}$ Showing that regional investment and regional domestic savings can diverge sharply, when at the national level those variables are highly correlated, those papers conclude, in fact, that external imbalances may happen more often and in a large scale at the regional level than among countries. Indeed, regions match the gap between these two variables resorting to external savings that flow into the region through the external disequilibrium. These analyses, however, rely as rule on a simplified procedure that reduces the concept of regional domestic savings $(S)$ to:

$$
S=\mathrm{GDP}-C
$$

where $C$ is the private (households and non-profit institutions) and public (general government) consumption on the regions. By the basic macroeconomic identity:

$$
\mathrm{GDP}=C+I+X-M
$$

where $I$ is the investment, and $X$ and $M$ the goods and services regional exports and imports, they easily get:

$$
S-I=(\mathrm{GDP}-C)-I=X-M=\mathrm{TB}
$$

\footnotetext{
1 As is designated the extended debate following Feldstein and Horioka (1980). For a general overview on this controversy, please address Obstfeld and Rogoff (1996), pp. 161-164 and Coakley et al. (1998).

2 Direct estimates of regional trade imbalances can be found as well in Sargento and Ramos (2003), who concluded for the Portuguese regions that those imbalances could exceed $20 \%$ of regional GDP, a score that as a rule would not be sustainable for countries.
} 
that being the reason why the focus is directed to the trade balance (TB) foregoing the current account $(\mathrm{CA}){ }^{3}$

Before proceeding with the main design of this paper, that consists of the comparison of the external disequilibria at the regional and national levels (by an approach that does not require data availability on regional savings, although focusing on trade balance as well), we briefly address, in Sect. 2, the theoretical question of why regions are different from countries registering wider external (current and, of course, trade) imbalances. There we argue that countries face sustainability constraints that as a rule, although having different impact in different kind of countries, limit them from running important deficits. However for regions we enumerate several reasons why they can avoid those constraints and are then allowed to enjoy benign imbalances, seeming not to cause serious trouble, rather benefiting the regional economies. We then come after, in Sect. 3, to presenting the basic idea of our empirical test for comparing regional and national trade imbalances, which consists on the decomposition of the cross-sectional variance of GDP growth within several spatial instances: the OECD countries, the 15 European Union (EU) countries that were already members before the 2004 enlargement, and the EU regions. At the regional level, where we had data only on investment rates up to 162 regions, we focus on the contribution of these rates fluctuations to that variance that we found to be consistent with our claim of relevant regional trade disequilibria. This conclusion is solely based on investment data, rather than on savings information. Section 4 encloses our results and Sect. 5 concludes.

\section{How can regions stand for larger external imbalances?}

The standard view in the economic literature, even at the countries level namely of the so-called intertemporal trade theory ${ }^{4}$ - is not that external imbalances hit economic efficiency, rather they may instead improve it. The argument is that some countries or regions, running external imbalances, can avoid sharp contractions on their consumption and/or investment, when a temporary shortfall occurs in their production, while other countries or regions with ample savings can use this channel for directing their excessive thrift outside the local (national or regional) economy.

\footnotetext{
3 The National Accounts adopts a broader concept of domestic savings $S^{N}=$ NDI $-C$ with NDI $=$ GDP + FI + NT, NDI being the National Disposable Income, FI the net factor income balance and NT the balance of net current transfers (these latter balances are not available, as a rule, at the regional level). Following the national concept $S^{N}-I=[(\mathrm{GDP}+\mathrm{FI}+\mathrm{NT})-C]-I=\mathrm{CA}$. For the sake of consistency, however, comparing an investment/savings gap at the regional and countries level requires an equivalent concept of savings on both. Armstrong et al. (1996) agree with this caution, defining savings for EU members in such a way which compares with the one used by Bayoumi and Rose (1993) for British regions.

4 See for instance Obstfeld and Rogoff (1996), chapters 1-3, for an extended overview of this theory. An alternative presentation of the external accounts models and of the imbalance issue may be found in Knight and Scacciavillani (1998).
} 
The problem with this efficiency approach is however that it ignores the sustainability issue. In fact, the foreigner agents underwriting the external imbalance bear a risk of loosing their capital. The point is then how prone those agents are to finance permanent and sometimes increasing deficits on external payments. This is a relevant issue, however, at the countries level, not for regions. In fact, we may find several reasons why the sustainability constraint does no apply to regions, or at least it is not so pressingly for them as it is for countries. ${ }^{5}$ At the current account level these reasons are:

- The existence of multiregional firms, that account for a considerable share of the regional economies, whose plants operating inside the regions are not very often independent legal entities, and so are not liable alone by their debt (on the theoretical ground a regional budget constraint should result from adding up the individual budget constraints of resident agents; but when some relevant agents are not legal entities, they do not face budget constraints from their own, and so that aggregated regional budget constraint does not exist);

- The multiregional nature of the financial system as well and of the great majority of the units belonging to it; in fact, in the international environment, households and corporations' foreign debt is seldom handled directly, but it is very often intermediated by the national financial system, that incurs the liability itself in the international markets; country risk is then to a great extent its financial system breakdown risk; for regions, however, the role of the financial system is quite different, as financial institutions usually operate all over the country, and they do not concentrate in their regional branches the risk deriving from their local customers;

- The lower legal capacity of regional and local governments that prevents the generation of a high sovereign-type risk at the regional level; regional and local governments are not immune from national laws and they have no capacity to protect private agents when they default;

- The supposed non-existence of reputational externalities ${ }^{6}$ at the regional scale (at the countries level these externalities may determine the credit rationing of some borrowers, that otherwise would be considered sound, but that are affected by the "country risk" when other borrowers default); on the contrary, it may happen that some regions benefit from the national

\footnotetext{
5 We have only found one paper that clearly asserts that the external imbalance sustainability does matter for regions: Thirlwall (1980). The main proposition in this article is that "no country or region (for very long) can grow faster than its balance-of-payments growth rate unless it can continually "finance" a rate of growth of imports in excess of the rate of growth of exports" (p. 421; italics ours). This above safeguard in italics really means that the non-existence of capital inflows is assumed rather than proofed. Thirlwall and Hussain (1982), a later paper that in fact only deals with countries, released explicitly that assumption, allowing for a current account deficit. The debate on the above proposition that would be known in literature by Thirlwall's Law (or the 45-degrees rule in Krugman 1989, designation), would proceed exclusively, as far as we know, at countries level, without any appeal to the regional peculiarity.

${ }^{6}$ For a discussion on this concept and its relevance for external disequilibrium, please address Catte (1998).
} 
solidarity of other regions, through an investment bias towards the regions of the very same country that is preferred to investing abroad.

- At finally, obviously regions do not have their own currency, and so there is not an exchange market and risk; (however several countries in Europe renounced, like regions, to their own currencies and are now sharing the Euro; interestingly, that that does not seem to have relieved national governments of worrying about their external deficits).

On the other hand, even when the current account is well balanced we may still find significant and sustainable disequilibria at the regional trade balance because:

- Some regions benefit of huge interregional (explicit or implicit) governmental transfers ${ }^{7}$ that substitute exports financing the net imports;

- Multiregional and sometimes even local corporations grant a large interregional income redistribution, paying dividends to their shareholders or interests to their lenders, sometimes residing outside of the region, or paying wages to employees living in neighboring regions.

For all these reasons, we do believe that the sustainability issue does not apply for regional deficits, ${ }^{8}$ in contrast to the efficiency approach that in our opinion remains valid. By the same token, capital mobility promotes economic efficiency, even if it induces important current and trade deficits, allowing investors to search for more profitable locations besides savings locations. In the remaining part of this paper, we then look for some empirical proof on higher frequency of sizeable imbalances for regions, given this argument of the irrelevance of sustainability at the regional level.

\section{Empirical evidence on trade imbalances: a test on spatial "risk sharing"}

The purpose of the following sections is to provide empirical evidence that trade imbalances happen more often with a considerable dimension, for EU regions, than they arise either for OECD countries or the $15 \mathrm{EU}$ countries that were members before the May 2004 enlargement (EU15). As a matter of fact, our prior expectation is that the EU15 may lie in some kind of an intermediate position between regional sharp trade imbalances and the more balanced regime typical of countries (here represented by the OECD members).

The basic idea of our test, that proceeds from Asdrubali et al. (1996) and Sorensen and Yosha (1998), is that economic agents - either at national or

\footnotetext{
7 Eurostat has promoted in several European countries pilot studies on general government regional accounts, with the aim of gauging this kind of transfers, whether they are explicit or merely implicit. For a description of this experience see Ramos (2000).

8 As a matter of fact we may acquiesce that this statement may depend on what we mean by regions. A very large region or a group of regions looks probably more "like a country" than "like a region" in many aspects. Large regions may then be more "financed-constrained", like countries, because reputational externalities develop, multiregional firms are not so prevalent, or there is a sizable regional financial system. In this paper, regions are to be seen as small ones, as the European regions (NUTS II) considered in the sections ahead.
} 
regional level - search for a smooth distribution of the private and public consumption $C$ over space (as they do over time as well). Variable $C$ should then (to some extent) be immune from idiosyncratic shocks in the level of production of the very country or region we are examining. This behavior, that those authors designated as "risk sharing", consists of the attempt to stabilize the fraction $k_{t}^{i}$ defined as:

$$
k_{t}^{i}=\frac{C_{t}^{i}}{C_{t}^{w}}
$$

where $i$ is the lower-level space, the country for a cross-country analysis or the region for the regional approach, and $w$ the high-level space, the world in the former case or the country in the regional one. In case of full risk sharing, $k_{t}^{i}$ becomes a constant, not depending on $t$ (neither on the lower-level space GDP hypothetically hit by idiosyncratic disturbance).

Our proposal, similar to the one of Asdrubali et al. (1996) and Sorensen and Yosha (1998), is then to proceed to the decomposition of the cross-sectional variance of shocks to GDP, here based on the identity ahead (please note that by (1): GDP $-I=\mathrm{TB}+C)$ :

$$
\mathrm{GDP} \equiv \frac{\mathrm{GDP}}{\mathrm{GDP}-I} \cdot \frac{\mathrm{TB}+C}{C} \cdot C
$$

Following those authors we easily reach:

$$
\begin{aligned}
\operatorname{var}(\mathrm{GDP} g r)= & \operatorname{var}(\Delta \log \mathrm{GDP}) \\
= & \operatorname{cov}[\Delta \log \mathrm{GDP}-\Delta \log (\mathrm{GDP}-I), \Delta \log \mathrm{GDP}] \\
& +\operatorname{cov}[\Delta \log (\mathrm{TB}+C)-\Delta \log C, \Delta \log \mathrm{GDP}] \\
& +\operatorname{cov}(\Delta \log C, \Delta \log \mathrm{GDP})
\end{aligned}
$$

Dividing both sides of the equality by the cross-sectional variance of the GDP growth rate var (GDPgr), we get:

$$
1=\beta_{1}+\beta_{2}+\beta_{3}
$$

where $\beta_{1}, \beta_{2}$ and $\beta_{3}$, that are the shares in the decomposition of the variance of GDPgr, coincide with the slopes obtained by the OLS of the regressions of $\Delta \log \mathrm{GDP}-\Delta \log (\mathrm{GDP}-I), \Delta \log (\mathrm{TB}+C)-\Delta \log C$, and $\Delta \log C$ on GDPgr.

Clearly, if there is full risk sharing, and therefore specific product disturbance does not spread at all into consumption, then $\operatorname{cov}(\Delta \log C, \Delta \log \mathrm{GDP})=0$ and $\beta_{3}=0$. When, on the other hand, $\beta_{3} \neq 0$, consumption fluctuations are not fully exempted from idiosyncratic impacts on GDP, and $1-\beta_{3}$ is to be regarded as the risk sharing degree among a conglomerate of (national or regional) economies.

If full or partial risk sharing does exist within a set of economies $\left(0 \leq \beta_{3}<1\right)$, then by (3) either $\beta_{1}$ or $\beta_{2}$ or both are positive. When $\beta_{1}$ is positive, we conclude 
that consumption stabilizing has been reached at the expense of investment. This happens because the investment rate (I/GDP) declines during recession or weak growth periods, but booms when production increase, making the most of positive temporary product shocks not affecting consumption.

When we have $\beta_{2}$ significantly positive, we may then assert that the risk sharing stabilizer mechanism is feed by external savings (measured in a broad sense by $-\mathrm{TB}$ ). The implication is that when the economy slows, economic agents lay their hands on the external savings to protect their consumption path, and also eventually for keeping their investment up (if $\beta_{1} \cong 0$ at the same time). On the other hand, when the economy grows faster than their partners, $\beta_{2}>0$ means that dependence on external savings lessens, or even that the economy exports excessive savings through a superavit TB $>0 . \beta_{1}$ and $\beta_{2}$ are of course the shares assigned to each one of these mechanisms in the risk sharing process.

In fact, at the country level (OECD and EU15), unlike regions, we went further decomposing $\beta_{2}$ - the contribution of external savings (gauged by $-\mathrm{TB}$ ) to the smoothing mechanism - as follows:

$$
\frac{\mathrm{TB}+C}{C} \equiv \frac{\mathrm{TB}+C}{-\mathrm{NT}-\mathrm{FI}+C} \frac{-\mathrm{NT}-\mathrm{FI}+C}{-\mathrm{FI}+C} \frac{-\mathrm{FI}+C}{C}
$$

implying:

$$
\beta_{2}=\beta_{21}+\beta_{22}+\beta_{23}
$$

where $\beta_{21}, \beta_{22}$ and $\beta_{23}$ are the slopes of the OLS regressions of the growth rates of the parts in (4) above on GDPgr. $\beta_{21}$ represents the contribution of the strict National Accounts measure of external savings, generated through the current account deficit $-C A$, to the risk sharing process (please take into account that $\mathrm{CA}$ is the difference between the numerator and the denominator in the first ratio above as $\mathrm{TB}=\mathrm{CA}-\mathrm{NT}-\mathrm{FI}) \cdot \beta_{22}$ is the share of international transfers to that process, and $\beta_{23}$ the contribution for consumption stabilizing of the factors income balance (that is supposed to be positive as well, as consumption of households that benefit from incomes from their oversea assets do not depend only on their domestic yields). ${ }^{9}$

Our problem however, at the regional level, in decomposing the variance of GDPgr for EU regions, was besides (5) that even for (3) we were only able to estimate the $\beta_{1}$ parameters. All the information we had available was for Gross Fixed Capital Formation (broadly, investment) for a maximum of 162

\footnotetext{
9 Bayoumi et al. (1999) proceeds to a direct measure of this mechanism looking at the dispersion of the ratio GNP/GDP through seven of the largest EU countries. They also apply the same approach - as a benchmark - to British regions, taking regional personal income as a proxy of GNP.
} 
EU regions over the period $1995-2000,{ }^{10}$ and of course for the corresponding regional GDP, only allowing for the $\beta_{1}$ estimation. Our idea was then to consider that if we produced evidence that $\beta_{1}$ has a significantly lower value for regions than in the cross-countries analysis, that may be seen as a signal of wider trade imbalances for regions, if we make the assumption that there is in fact a risk sharing process among regions belonging to a country, as there is within some groups of countries. This hypothesis (that leads to $\beta_{3}<1$ ) was assumed at the regional level, after it had been statistically confirmed for OECD members, and above all in a more clear way for EU15. In effect, if $\beta_{3}<1$ for regions similarly to countries, and we get a low value for $\beta_{1}$, then by (3), we should have at the regional level a higher value for $\beta_{2}$ comparing with countries. This would mean that the assumed interregional risk-sharing process is mainly performed through the trade imbalance mechanism. This evidence is consistent with our claim that trade imbalances should be more prevalent for regions than for nations.

\section{Some results}

The results we obtained for OECD member countries ${ }^{11}$ are reproduced in Table $1 .{ }^{12}$ The most prominent result is that, unlike our expectations, the estimated values of $\beta_{3}$ are not always less than unity, in a statistical significant way, exceeding even that value in 3 out of the 8 years of our analysis.

This result may cast some doubt on the occurrence of the risk sharing phenomenon itself at cross-country level. Nevertheless, if this kind of behavior does not prevail among OECD countries, that is not because investment does not play its expected role: the investment rate follows clearly a pro-cyclical path $\left(\beta_{1}>0\right.$, significantly for most of the cases), which would have allowed a strong consumption stabilization, if $\beta_{2}<0$ had not arisen in a systematic way.

In fact, because $\beta_{2}<0$, there is no evidence that OECD countries resort to external savings to offset adverse and idiosyncratic shocks to GDP, in contrast

\footnotetext{
10 We based our study mainly on NUTS II regions' data, extracted at 29/12/2004, from the Regio database, through the site of the Eurostat (except for Portugal where more complete national statistics were available). Information for regional investment was not available for Spain and UK. For Germany we used NUTS I instead of NUTS II. We excluded countries that are not split by regions at NUTS II level.

11 The data we based these estimates were extracted from the site of the OECD at 30/12/2004. The same data have been used for EU15 estimates as well.

12 As can easily be checked by adding up the $\beta$ s in Table 1, Eq. (3) of the main text is not exactly confirmed by these results. The reason for that outcome is that basic macroeconomic identity (1) is not respected itself in the original data, which is to say in the OECD 1995 constant prices data we dealt with. That happens because, in modern National Accounts systems, constant prices aggregates are always, in a first step, estimated at the previous year prices, being the fixed year constant prices values obtained after by a chain-linking process. This procedure, however, generates an unavoidable discrepancy, in what is known in National Accounts jargon by the "additivity problem". For further discussion of this procedure and of the relevance of the discrepancy, please see Office for National Statistics UK (2002). Besides this problem, however, in the data we used (source OECD) identity (1) is also infringed at current prices by some countries, namely in a relevant way by Turkey.
} 
Table 1 Decomposition of the cross-sectional variance of shocks on GDP growth rates, 1996-2003, OECD Members

\begin{tabular}{llll}
\hline & $\beta_{1}$ & $\beta_{2}$ & $\beta_{3}$ \\
\hline 1996 & $0.578^{\mathrm{b}}(2.005)$ & $-0.559(-1.454)$ & $1.053^{\mathrm{a}}(5.013)$ \\
1997 & $0.434^{\mathrm{a}}(3.889)$ & $-0.046(-0.231)$ & $0.611^{\mathrm{a}}(5.096)$ \\
1998 & $0.877^{\mathrm{a}}(2.111)$ & $-1.016(-1.230)$ & $1.045^{\mathrm{a}}(3.753)$ \\
1999 & $0.375^{\mathrm{b}}(1.577)$ & $-0.116(-0.387)$ & $0.665^{\mathrm{a}}(6.857)$ \\
2000 & $0.192(1.028)$ & $-0.046(-0.156)$ & $0.844^{\mathrm{a}}(5.321)$ \\
2001 & $0.684^{\mathrm{a}}(2.121)$ & $-0.691(-0.750)$ & $1.032^{\mathrm{a}}(3.444)$ \\
2002 & $0.421^{\mathrm{b}}(1.768)$ & $-0.126(-0.835)$ & $0.636^{\mathrm{a}}(2.379)$ \\
2003 & $0.386^{\mathrm{b}}(1.717)$ & $-0.149(-0.461)$ & $0.677^{\mathrm{a}}(4.451)$ \\
\hline
\end{tabular}

In this table, as in the others ahead, t-ratios are given in parentheses. These statistics are based on "heteroscedasticity consistent covariance matrixes", of the kind HC3, that following Long and Ervin (2000) are preferable for small samples as ours. In spite of this cautionary procedure we corrected for heteroscedasticity whenever we detected it (namely in Table 5 results)

${ }^{\mathrm{a}}$ Coefficients different from zero significantly at $5 \%$, and ${ }^{\mathrm{b}}$ Those that are significant at $10 \%$

Table 2 Decomposition of the Cross-Sectional Variance of Shocks on GDP Growth Rates, 19962003, EU15 countries

\begin{tabular}{lccl}
\hline & $\beta_{1}$ & $\beta_{2}$ & $\beta_{3}$ \\
\hline 1996 & $0.342^{\mathrm{a}}(2.266)$ & $0.011(0.045)$ & $0.646^{\mathrm{a}}(2.873)$ \\
1997 & $0.284^{\mathrm{a}}(3.498)$ & $0.299^{\mathrm{b}}(1.896)$ & $0.532^{\mathrm{a}}(4.192)$ \\
1998 & $0.221^{\mathrm{a}}(4.425)$ & $0.072(0.506)$ & $0.654^{\mathrm{a}}(11.155)$ \\
1999 & $-0.024(-0.086)$ & $0.406^{\mathrm{a}}(2.554)$ & $0.571^{\mathrm{b}}(1.978)$ \\
2000 & $-0.133(-0.911)$ & $0.453^{\mathrm{a}}(3.843)$ & $0.723^{\mathrm{b}}(1.936)$ \\
2001 & $-0.186(-0.290)$ & $0.388^{\mathrm{b}}(1.956)$ & $0.774^{\mathrm{a}}(2.590)$ \\
2002 & $0.041(0.157)$ & $0.325(1.004)$ & $0.633^{\mathrm{b}}(2.083)$ \\
2003 & $0.469^{\mathrm{b}}(1.774)$ & $-0.186(-0.717)$ & $0.663^{\mathrm{a}}(5.021)$ \\
\hline
\end{tabular}

${ }^{a}$ Coefficients different from zero significantly at $5 \%$

${ }^{\mathrm{b}}$ Those that are significant at $10 \%$

to our theoretical expectations. In fact, trade deficits seemed to widen when economies boom and to narrow when growth slows, dominated very likely by the behavior of imports, that very often correlate with the product cycle.

However, if we look at the EU15 instead of the OECD members, the picture we obtain is quite different (Table 2). The most outstanding finding for EU15 is that there is now evidence that supports the risk sharing phenomenon: that is $\beta_{3}<1$ always. On the other hand, consistently, external savings seem to play its theoretical predicted role in stabilizing countries consumption shares, as we estimated $\beta_{2}>0$ for several years (although these estimates are often not statistically significant). Furthermore, investment does not follow the same strict pro-cyclical behavior that we found for OECD countries, as we now obtain clear lower values for $\beta_{1}$ than we had before for $\operatorname{OECD}\left(\beta_{1}\right.$ became even negative for a few years, although non-significantly).

In our view, this combination of a mostly stable investment over the cycle with a smooth consumption path may be a signal that EU15 countries can 
Table 3 Decomposition of $\beta_{2}-$ OECD Members

\begin{tabular}{llll}
\hline & $\beta_{21}$ & $\beta_{22}$ & $\beta_{23}$ \\
\hline 1996 & $-0.655(-1.300)$ & $-0.037(-0.706)$ & $-0.042(-0.916)$ \\
1997 & $-0.227^{\mathrm{b}}(-1.815)$ & $-0.024(-1.631)$ & $0.158(1.006)$ \\
1998 & $-1.387^{\mathrm{b}}(-1.789)$ & $0.061(0.929)$ & $0.012(0.069)$ \\
1999 & $-0.634^{\mathrm{a}}(-2.337)$ & $0.052^{\mathrm{a}}(2.261)$ & $0.174(0.634)$ \\
2000 & $-0.675^{\mathrm{b}}(-1.701)$ & $0.009(0.269)$ & $-0.067(-0.640)$ \\
2001 & $-0.270(-0.890)$ & $0.098^{\mathrm{a}}(2.196)$ & $0.092(0.402)$ \\
2002 & $-0.465^{\mathrm{a}}(-2.196)$ & $0.027(0.684)$ & $0.131(0.681)$ \\
2003 & $0.035(0.070)$ & $-0.069(-1.082)$ & $-0.028(-0.486)$ \\
\hline
\end{tabular}

Except Hungary, Turkey and Luxemburg. Japan, Mexico, Poland and Switzerland are excluded as well in 2003

${ }^{a}$ Coefficients different from zero significantly at $5 \%$

${ }^{\mathrm{b}}$ Those that are significant at $10 \%$

already benefit, almost "like regions," of an unrestricted access to external savings, turning sometimes into relevant external imbalances by country standards (Portugal, Greece, Spain). In fact, it is quite plain from Table 2 how different are the results between EU15 in comparison with the OECD countries (all the more so since the OECD comprises the $15 \mathrm{EU}$ countries out of its 30 members).

At the country level, it still is interesting, before proceeding to the crossregional analysis through the EU, to look, even briefly, at Tables 3 and 4, that have the purpose of decomposing $\beta_{2}$ for OECD and EU15 member states, as suggested by equations (4) and (5) ${ }^{13}$. The first relevant conclusion in this analysis concerns that we met $\beta_{21}<0$ for OECD countries (Table 3 ), meaning that the current account $C A$ itself (and so the capital account in the conventional sense) is the reason why external savings do not promote risk sharing among this group of countries. Indeed, our results suggest that international capital markets may have a perverse behavior, tightening the access to external savings when countries do need it more, that is to say when growth slows and recession appears. The same kind of reaction by the capital markets may not arise however among EU15 countries, according to Table 4, as $\beta_{21}$ exhibits for this latter group a more reduced value not significantly different from zero (though still negative). If external savings have a role in the EU15, through the trade

\footnotetext{
13 Remark that as happened before with Eq. (3), Eq. (5) also comes to be infringed, as adding up $\beta_{21}, \beta_{22}$ and $\beta_{23}$ over the rows of Tables 3 and 4 does not match the corresponding estimates to $\beta_{2}$ at Tables 1 and 2 . The reason now is that we could not proceed to this analysis at constant prices, as we have not proper deflators for NT and FI, having we opted instead by using the current prices of the dependent variables in the decomposition of $\beta_{2}$. This procedure is justified because we are computing growth rates of ratios, so working at current prices leads to exactly the same results than deflating the numerator and the denominator by the same deflator. The reason for the expressive discrepancy we met over (5) is that being the deflators of TB and $C$ very unlike, it comes that estimating $\beta_{2}$ with nominal values is quite different from using constant prices on (TB $\left.+C\right) / C$. A second obvious reason for the mismatch in (5) is that in computation of Tables 3 and 4 results we were not able of including all the countries we had used in Tables 1 and 2.
} 
Table 4 Decomposition of $\beta_{2}-$ EU15 Countries

\begin{tabular}{llcc}
\hline & $\beta_{21}$ & $\beta_{22}$ & $\beta_{23}$ \\
\hline 1996 & $-0.013(-0.034)$ & $0.057(1.578)$ & $-0.063(-0.551)$ \\
1997 & $-0.032(-0.246)$ & $-0.016(-0.302)$ & $0.207^{\mathrm{a}}(2.212)$ \\
1998 & $-0.308(-1.648)$ & $0.010(0.152)$ & $0.317^{\mathrm{a}}(2.701)$ \\
1999 & $-0.037(-0.380)$ & $0.018(1.003)$ & $0.426(0.596)$ \\
2000 & $-0.006(-0.035)$ & $0.013(0.169)$ & $-0.028(-0.099)$ \\
2001 & $-0.096(-0.389)$ & $0.108(1.438)$ & $0.355^{\mathrm{a}}(2.932)$ \\
2002 & $-0.365(-1.628)$ & $-0.021(-0.309)$ & $0.392^{\mathrm{b}}(1.778)$ \\
2003 & $-0.285(-1.288)$ & $-0.017(-0.464)$ & $-0.073(-0.446)$ \\
\hline
\end{tabular}

Except Luxemburg

${ }^{\text {a }}$ Coefficients different from zero significantly at $5 \%$

${ }^{\mathrm{b}}$ Those that are significant at $10 \%$

Table 5 Share of the cross-sectional variance of the GDP growth absorbed by the investment rate growth $\left(\beta_{1}\right)-$ EU Regions

\begin{tabular}{lc}
\hline & $\beta_{1}$ \\
\hline 1996 & $-0.067(-0.757)$ \\
1997 & $0.128^{\mathrm{a}}(1.925)$ \\
1998 & $0.121^{\mathrm{a}}(1.685)$ \\
1999 & $0.122(1.461)$ \\
2000 & $-0.006(-0.055)$ \\
2001 & $0.225(1.210)$ \\
\hline
\end{tabular}

Except the Spain and UK regions

${ }^{\mathrm{a} C o e f f i c i e n t s ~ d i f f e r e n t ~ f r o m ~ z e r o ~ s i g n i f i c a n t l y ~ a t ~} 10 \%$

balances TB, contributing to a risk sharing process, that owes interestingly to the stabilizer role of the factor income balance $\left(\beta_{23}\right)$ and not as might be expected to the transfers operated through the European budget (reflected in $\beta_{22}$ ).

As for the regional analysis within the EU, all we were able to do was estimate $\beta_{1}$ that stands for the investment impact on the smoothing consumption process. In this procedure, we have excluded Aland, a Finnish archipelago that accounts for only 26,000 inhabitants, and that acted as an outlier. On the other hand, we used GLS instead of OLS (for correcting for heteroscedasticity), as we had some evidence, in preliminary estimates, on different residual variance by countries within our sample of regions.

Table 5 depicts our results that took into account in each year the whole set of European regions which we are able to use. Note the low value to $\beta_{1}$, smaller than the one we estimated for countries, whether we dealt with OECD countries, or even in the EU15 case when these estimates were positive. It appears that the absorption of a GDP disturbance that we assumed to exist within the $\mathrm{EU}$, at regional level, as among countries, should have been left to the external savings mechanism (through TB imbalances) because empirical data suggest that investment did not carry relevantly that burden. 
Table 6 Share of the cross-sectional variance of the GDP growth absorbed by the investment rate growth $\left(\beta_{1}\right)$ for some European countries

\begin{tabular}{llllllll}
\hline & Germany & Belgium & France & Greece & Netherl. & Italy & Poland \\
\hline 1996 & $-1.990^{\mathrm{a}}$ & -0.588 & $0.191^{\mathrm{a}}$ & -1.087 & 0.419 & -0.226 & - \\
& $(-2.878)$ & $(-1.797)$ & $(2.884)$ & $(-1.135)$ & $(1.327)$ & $(-0.712)$ & \\
1997 & -1.149 & 0.024 & 0.148 & -0.242 & $0.990^{\mathrm{a}}$ & -0.060 & - \\
& $(-1.506)$ & $(0.047)$ & $(1.268)$ & $(-1.135)$ & $(2.343)$ & $(-0.378)$ & \\
1998 & $1.626^{\mathrm{a}}$ & -0.231 & $-0.439^{\mathrm{a}}$ & -0.293 & 0.293 & 0.059 & - \\
& $(2.648)$ & $(-0.603)$ & $(-3.099)$ & $(-0.371)$ & $(1.264)$ & $(0.278)$ & \\
1999 & -0.305 & -0.160 & -0.188 & - & $-0.666^{\mathrm{a}}$ & 0.378 & -0.072 \\
& $(-0.415)$ & $(-0.363)$ & $(-1.449)$ & & $(-4.016)$ & $(1.199)$ & $(-0.363)$ \\
2000 & $0.941^{\mathrm{a}}$ & -0.178 & -0.141 & - & - & -0.313 & -0.178 \\
& $(2.335)$ & $(-0.633)$ & $(-1.107)$ & & - & $(-0.991)$ & $(-0.427)$ \\
2001 & 0.196 & -0.479 & - & - & - & 0.505 & - \\
& $(0.190)$ & $(-1.047)$ & & & & $(1.583)$ & \\
$N$ & 16 & 11 & 26 & 13 & 12 & 20 & 16 \\
\hline
\end{tabular}

${ }^{\mathrm{a} C o e f f i c i e n t s ~ d i f f e r e n t ~ f r o m ~ z e r o ~ s i g n i f i c a n t l y ~ a t ~} 5 \%$

After obtaining $\beta_{1}$ for the whole set of European regions, we further proceeded with the estimation of the same coefficient for each country separately (although we confined our analysis to countries with at least ten regions). These countries results, reported in Table 6, confirm that investment does not behave at regional level in a way that induces consumption smoothing, so if that aim is achieved, as we assume it is, it was the trade imbalance mechanism that was compelled to play that role. We even obtained for the most of the time $\beta_{1}<0$, although estimates are not, very often, accurate enough (samples by countries are too small) for ensuring that they are significantly different from zero.

At last, the available statistical information for EU regions (which confines to investment rates) was able to provide yet other curious stylized fact. Indeed, we found that, despite the fact that regional investment did not reproduce the product cycle, it is notwithstanding a much more unstable variable at the regional level than for countries. When we look at the 162 regions for which data are available at our database, we concluded that in 116 cases we obtained a higher standard deviation in the regional investment rate than in the country where the region is located (if we had looked at the coefficient of variation instead that number would had been 119). This result may mean that investment is exposed to an exogenous disturbance one that is not correlated with production that should be more relevant for regions that at the country level. If investment shocks do not spill into the regional GDPs and they do not disturb consumption, as we assumed, then the only possible outcome is that they are offset by the external trade, providing a further reason for enlarged trade imbalances.

An interesting additional detail from this analysis is that among the 46 regions where the investment rate is exceptionally more stable than in the corresponding country, we find 21 out of the 26 French regions. France emerges then as a peculiar case, with a more unstable investment rate for the country than for its regions. 
When we have in mind a cross-sectional standard deviation, instead of basing our analysis on time series, we find again a larger disparity among European regions than for countries. The cross-sectional standard deviation of the average investment rate, between 1995 and 2001, for 162 European regions amounts to 0.0549 , compared with 0.0250 for the EU15, 0.0352 for the OECD and 0.0361 for the 19 countries of the EU that are members of the OECD as well. When we calculated however cross-sectional standard deviations within each EU country, we met several cases with a reduced value for that indicator, even below that recorded at EU15. France and Sweden deserve mention for having regularly, in the course of time, cross-sectional standard deviations lagging behind the corresponding statistics for EU15, that in average terms were 0.0178 and 0.0130 , respectively. As a matter of fact, the general rule seems to be that the regional disparity on investment rates moved in step with regional asymmetries. For instance, Germany really urged on investing in its laggard regions attaining a cross-sectional standard deviation of the average investment rate of 0.0998 over the period 1995-2001. These interregional disparities should have lead to wide but welcomed trade deficits in those poorest regions.

\section{Main conclusions}

This paper brought forward a relatively wide set of empirical evidence supporting the idea that EU regions meet more frequently trade imbalances of relevant size than countries can stand. It would appear that regional (namely interregional) exports and imports are beyond the scope of official statistics, not allowing for a direct computation of trade imbalances. On the other hand, as statistical information on domestic consumption and savings is also unavailable, on a regular basis, for European regions, we were unable to perform even a more indirect assessment of regional external imbalances. With the purpose of overcoming these limitations, we then settled on an approach that makes the proof that investment (basically the information we have at regional level) behaves consistently with our claim of wider trade imbalances for regions, relying on an assumption we deemed reasonable, namely that, at regional level, economic agents do smooth consumption in a similar way shown in comparable cross-countries analysis.

Of course, the idea that regions can incur in significant trade imbalances that may be precluded at the country level was also discussed on theoretical grounds. Our main argument was that the sustainability constraints, that limit countries from running important external deficits, do not apply for regions or at least they are not as pressing for them as they are for countries. As regions are free of this sustainability jacket, they become capable of fully profiting from an efficiency gain that, as we argued, may be provided through external imbalances. In fact, although we cannot say a priori that regions must run trade deficits rather than surpluses, or the opposite (not at least as deficits on some regions have inevitably their counterpart as surpluses somewhere else), we argued that efficiency is improved when capital flows from the regions where it is abundant 
(generating trade surpluses) to other regions where it is scarce (the less developed ones) causing deficits in these regions. On the other hand, if a region has sound growth expectations, it may also be economically efficient to anticipate consumption at the expense even of a trade deficit. Therefore, although we concluded that regions run more frequently sizable deficits, we do not pretend that they should worry with that fact (on the contrary they benefit with it very often). External balance (or imbalance) shall not be a policy target for regional policy, although it might be - if that information exists - a useful indicator of the regional stance.

A related question to our main issue on the relevance of regional trade imbalances is if countries that belong to a monetary union, such as the Euro-zone countries, may to a certain extent be seen to be acting "like regions", running as well significant but also benign imbalances. This is of course a question with very important policy implications in Europe, because it may lead to the crucial conclusion, against the conventional wisdom, that the external deficits in Eurocountries are innocuous, or at least are not as dangerous as they used to be. As a matter of fact, the preliminary evidence we produced may support that idea, as EU15 countries share the risk associated with idiosyncratic product shocks in such a way that mimics regions' behavior, and is thus distinct from the OECD countries. In effect, they seem to be more successful on the consumption immunization process after the GDP specific disturbance, without resorting as much to an investment compensating mechanism as would be the case for other OECD countries. The avoidance of a sharp impact on both consumption and investment can only be allowed by a wider access to external savings, at expense of course of more pervasive trade imbalances.

However, we are very cautious about this last conclusion. The widespread feeling of national policy authorities, all over the Europe, is that they should continue to keep a close eye on the external position of their countries. On the other hand it must be stressed that, in spite of the empirical evidence we obtained, several theoretical arguments we put forward for regions, showing that they are able to avoid the sustainability constraints, do not apply plainly for Euro-countries. Nevertheless, being careful about radical conclusions for the EU countries does not mean that we do not accept that in the future, with greater integration, the importance of taming current external imbalances will very likely lessen. Furthermore, if that happens, far from jeopardizing economic growth and development, it will enhance economic efficiency throughout Europe.

\section{References}

Armstrong H, Balasubramanyam V, Salisu M (1996) Domestic savings, intra-national and intraEuropean Union capital flows, 1971-1991. Eur Econ Rev 40:1229-1235

Asdrubali P, Sørensen B, Yosha O (1996) Channels of interstate risk sharing: United States 1963 1990. Q J Econ 111:1081-1110

Bayoumi T, Rose A (1993) Domestic savings and intra-national capital flows. Eur Econ Rev 37:1197-1202 
Bayoumi T, Sarno L, Taylor M (1999) European capital flows and regional risk. Manchester School 67: 21-38

Catte P (1998) Current accounts: are they still relevant for and within a monetary union? In: Current account imbalances in East and West: do they matter? Oesterreichische Nationalbank, Vienna

Coakley J, Kulasi F, Smith R (1998) The Feldstein-Horioka puzzle and capital mobility: a review. Int J Financ Econ 3: 169-188

Decressin J, Disyatat P (2000) Capital markets and external current accounts: What to expect from the Euro" IMF Working Paper, WP/00/154

Dekle R (1996) Saving-investment associations and capital mobility: On the evidence from Japanese regional data. J Int Econ 41: 53-72

Feldstein M, Horioka C (1980) Domestic saving and international capital flows. Econ J 90:314-329

Helliwell J McKitrick R (1999) Comparing capital mobility across provincial and national borders. Can J Econ 32: 1164-1173

Knight M, Scacciavillani F (1998) Current accounts: What is their relevance for economic policymaking? IMF Working Paper, WP/98/71

Krugman P (1989) Differences in income elasticities and trends in real exchange rates. European Econ Rev 33: 1031-1046

Long S, Ervin L (2000) Using heteroscedasticity consistent standard errors in the linear regression model. Am Stat 54: 217-224

Obstfeld M, Rogoff K (1996) Foundations of international macroeconomics. The MIT Press, Cambridge: London

Office for National Statistics UK (2002) Annual chain-linking in the UK National Accounts - Draft. In: Seminar "Introduction of chain indices in National Accounts", Luxembourg (unpublished)

Ramos P (2000) The regional accounts of the general government: an application to Portugal. J Econ Soc Mea 26: 153-171

Sargento A, Ramos P (2003) Input-output based methodology for the estimation of interregional trade matrixes in Portugal. In: $50^{\text {th }}$ Annual North American meetings of the regional science association international, Philadelphia (unpublished)

Sørensen B, Yosha O (1998) International risk sharing and European monetary unification. J Inte Econ 45: 211-238

Thirlwall A (1980) Regional problems are "balance-of-payments" problems. Reg Stud 14: 419-425

Thirlwall A, Hussain M (1982) The balance of payments constraint, capital flows and growth rate differences between developing countries. Oxford Econ Pap, New Ser 34: 498-510 